\title{
Total number of immunocompetent cells in the normal rat epididymis and after vasectomy
}

\author{
P. Hooper ${ }^{1}$, E. Smythe ${ }^{1}$, R. C. Richards ${ }^{1 *}$, C. V. Howard ${ }^{2}$, \\ R. V. Lynch ${ }^{1}$ and D. I. Lewis-Jones ${ }^{1}$ \\ ${ }^{I}$ Reproductive Biology Unit, Department of Human Anatomy and Cell Biology, and ${ }^{2}$ Department of Fetal \\ and Infant Pathology, University of Liverpool, L69 3BX, UK
}

The aim of this study was to make unbiased quantitative estimates of the number of T8 cytotoxic cells and T4 helper cells and macrophages in the head and tail of rat epididymides, using newly developed design-based stereological methods in fertile control animals, and to compare these with results from vasectomized animals. The location of these cells within the intra- and interepithelial compartments of the epididymis was also studied. In control animals, both the T4 helper cells and macrophages and T8 cytotoxic cells were found in significantly higher numbers $(P<0.01)$ in the head interepithelial location than in the intraepithelial site. In addition, there were significantly more $(P<0.01)$ T8 cytotoxic ceils in the tail interepithelial region. Within the head region of vasectomized rats, there was a significant increase in T8 cytotoxic cells in the intraepithelial location $(P<0.01)$, and a decrease in T4 helper cells and macrophages in the interepithelial region $(P<0.05)$. Serum samples from vasectomized animals, when compared with those from control animals, showed a significant increase in cytotoxic antisperm antibody. This suggests that, in response to the increased spermatozoal antigenic absorption that takes place in the epididymis after vasectomy, the immune system redistributes its $T$ cell subsets to modify the immune tolerance that may occur.

\section{Introduction}

The immunogenicity of spermatozoa and testicular tissue was first described by Landsteiner (1899) and Metchnikoff (1899). Since then anti-sperm antibodies have been studied extensively in serum and seminal plasma and their role in male subfertility has been recognized (Rumke, 1954; Wilson, 1954). Halim and Antoniou (1973) demonstrated the presence of antisperm antibodies in the serum or seminal plasma of $8-13 \%$ of infertile men. However, men with demonstrable antisperm antibodies often father children and this has given rise to the suggestion that any decreased fertility due to the presence of these antibodies may depend on the antibody titre (Rumke et al., 1974). Indeed, it is now generally accepted that only serum or seminal plasma titres of greater than 1:32 should be regarded as significant in respect of their effect on fertility.

Human semen has been described as an 'antigenic nightmare' (Jones, 1976) and it is clear that in the normal fertile male, there must be mechanisms by which this plethora of antigenic material within the reproductive tract is sequestered from the immune system. Indeed, intraepithelial lymphocytes that may be involved in this process were first described in the rat epididymis by Reid and Cleland (1957). More recent work using immunocytochemistry identifies $B$ and $T$ cells in the human epididymis, with suppressor/cytotoxic (T8) cells pre-

*Correspondence.

Revised manuscript received 17 February 1995 dominating (Richie et al., 1984; El-Demiry et al., 1985). The role of these cells in controlling the humoral immune response by $\mathrm{B}$ cells has led to suggestions that they are responsible for sequestering antigenic material in and around the reproductive tract before it can elicit a systemic immune response. How this might be achieved is unknown, but it may occur in two ways: (i) the blood-epididymis barrier forms tight junctions between principal cells that prevent leakage of autoantigen out of the epididymal lumen; and (ii) the basal cells exhibit a tissue-fixed macrophage-specific antigen and show structures similar to macrophages under the electron microscope, which suggests that they phagocytose any leaking soluble material (Yeung et al., 1994).

In addition to its function of sperm storage and maturation, the epididymis is also the site of maximal breakdown and resorption of unejaculated spermatozoa. There is very little evidence that phagocytosis of whole spermatozoa is accomplished by the epithelial cells in the normal epididymis. However, there is evidence that transcytosis across these cells occurs, which permits the transfer of sperm antigen out of the lumen of the epididymis. These antigens may be free and soluble, resulting from the normal degradation of epididymal spermatozoa, and come into contact with cells of the immune system in the subepithelial tissue (Pollanen et al,, 1994). This has led El-Demiry et al. (1985) to postulate that this is why T8 cells are more abundant here than in the rest of the male genital tract. Mechanical obstruction of the vas deferens, as in 
vasectomy, may overwhelm these mechanisms by greatly increasing the antigenic load presented to the epididymal epithelium. Phadke and Padukone (1964) demonstrated an increased incidence of antisperm antibodies in the serum of previously fertile males after vasectomy. This may, at least in part, explain the disappointing results of vasectomy reversal, in terms of pregnancies, in those patients in which a satisfactory re-anastomosis has been achieved.

The basic sampling unit in biology is the organism. Usually the most sensitive index of change between groups of animals is the total quantity of the feature of interest. The past decade has seen the development of a family of design-based, assumption free, three-dimensional measurement techniques based on uniform random stereological sampling (Howard, 1990). If the sampling design is followed strictly, these techniques are guaranteed to be free from systematic bias.

The total number of objects in a space can be estimated from the product of their concentration in that space and the actual volume of the space, i.e.

$$
\text { est } N_{\text {(Total) }}=N_{V(\text { lymphocytes epididumis) }} \times V o l_{\text {(epididymis) }}
$$

Where $N_{V \text { (lymphocytes epididymis) }}$ is the number of lymphocytes per unit volume of epididymis and $V o l_{\text {(epididymis) }}$ is the volume of the epididymis estimated by Cavalieri's Principle.

In this study, the total volume of the epidymis was estimated by Cavalieri's Principle and the number of lymphocytes per unit volume by the physical dissector technique (Sterio, 1984; Gundersen, 1986). Worked examples of the application of this technique are given by Pakkenberg and Gundersen (1988) in the brain and by Hinchliffe et al. (1991) in the kidney.

These stereological methods are highly efficient and yield estimates in which the coefficient of error (Braendgaard et al., 1990 ) is generally $<10 \%$ and, provided the design is followed, they are guaranteed to be free from both sampling and systematic biases. The aim of the present study was to make quantitative estimates of the number of T8 suppressor/ cytotoxic cells and T4 helper cells and macrophages in the epididymis of fertile control animals and compare these with estimates from experimental animals in whom antisperm antibody production has been evoked by obstruction of the vas deferens. This required very little adaptation of the established methodology demonstrated by Pakkenberg and Gundersen (1988) and Hinchliffe et al. (1991). The main change to the protocol was to use frozen rather than paraffin wax sections. However, the mean thickness of the sections was known and in the physical dissector method section collapse after cutting does not bias the results. Therefore, the method could be applied accurately.

\section{Materials and Methods}

\section{Animals}

Four sets of two littermates, inbred, sexually mature, male Wistar albino rats, weighing approximately $250 \mathrm{~g}$, were used in the study. They were kept in Perspex and wire cages and given a standard rat diet and water. The rats from each litter were placed randomly into either the experimental or control groups.
All animals were anaesthetized with ether and maintained throughout surgery under this type of anaesthesia. Under sterile conditions, a midline abdominal incision was made and the abdominal cavity exposed. Both testes were removed from the scrotum in turn, by traction of the fatty body, delivering them through the internal inguinal ring into the abdominal cavity. In the experimental group, bilateral obstruction of the vas deferens at its midpoint between the cauda epididymis and urethra was effected by cutting between two 5/0 silk ligatures and tying-back the ends. The testes were then returned carefully to the scrotum; the abdominal incision was closed in layers; and the animal returned to its cage to recover. In the control group, the above procedures were carried out and the testicular artery and vas deferens were identified and manually manipulated but the vas deferens was not ligated or cut. All animals were then kept for three months before being killed.

At this time, each animal was again anaesthetized and both testes and associated structures were removed via a central abdominal incision. The epididymis was dissected away from the testis, cleared of fat and divided into head and tail by making a division through the corpus epididymis midway between the caput and cauda regions. These were then set in fixing gel, quick frozen in liquid nitrogen and stored at $-70^{\circ} \mathrm{C}$ until required. While the animal was anaesthetized, the heart was exposed by thoractomy and approximately $5 \mathrm{ml}$ of blood removed from the left ventricle. The rats were then killed under anaesthesia by separating the great vessels from the heart. Blood samples were centrifuged at $100 \mathrm{~g}$ for $5 \mathrm{~min}$ and the supernatant serum removed by pipette. Serum samples were divided into $200 \mu \mathrm{l}$ aliquots and frozen at $-20^{\circ} \mathrm{C}$. They were later analysed for cytotoxic antisperm antibody by the techniques described by Boyse et al. (1964) and Johnson (1968).

\section{Immunocytochemistry}

Frozen sections, $5 \mu \mathrm{m}$ thick, were cut on a Bright 5030 retracting microtome, at $-38^{\circ} \mathrm{C}$. Each section was collected on a slide pre-coated with $10 \mu \mathrm{l} 0.1 \%(\mathrm{w} / \mathrm{v})$ poly-L-lysine in distilled water (Sigma, Poole; molecular weight: $150000-$ 300 000). Slides were labelled and air-dried for $1 \mathrm{~min}$ before the sections were fixed in acetone at $-25^{\circ} \mathrm{C}$ for $15 \mathrm{~min}$. The slides were then air-dried, stored at $-25^{\circ} \mathrm{C}$ and stained within 2 days of cutting.

Sections were incubated in a 1:40 dilution of monoclonal antibody (either OX-8 A or W3-25 A; Serotec Ltd, Oxford) for $60 \mathrm{~min}$ in a moist atmosphere. The primary antiserum was discarded and the slides rinsed in a jet of Tris washing buffer; this buffer was made by dissolving $60.55 \mathrm{~g}$ of Trizma Base (Sigma) and $85.2 \mathrm{~g} \mathrm{NaCl}$ in $500 \mathrm{ml}$ distilled water, adjusting the $\mathrm{pH}$ to 7.6 with $1 \mathrm{~mol} \mathrm{HCl} \mathrm{l}^{-1}$ and making the volume up to $1 \mathrm{l}$; to $100 \mathrm{ml}$ of this solution $100 \mathrm{ml}$ of Triton $X-100$ (Sigma) was added and the volume adjusted to II.

The slides were then given four further washes for $2 \mathrm{~min}$ each with the same solution. The process was repeated using the secondary, rabbit anti-mouse serum 1:80 dilution (Z259: Dako, High Wycombe) absorbed with $2.5 \mu \mathrm{l}$ of normal rat serum per $50 \mu \mathrm{l}$ of rabbit anti-mouse serum at $24^{\circ} \mathrm{C}$ for $24 \mathrm{~h}$, and tertiary, mouse alkaline phosphatase anti-alkaline phosphatase 1:20 dilution (Z651: Dako), antisera, each of which was 
left for $30 \mathrm{~min}$. The slides were developed by leaving them in a Coplin jar for $10 \mathrm{~min}$ with freshly prepared substrate solution. This solution was prepared (using reagents from Sigma) by dissolving $15 \mathrm{mg}$ naphthol AS-MX phosphate-free acid in $0.5 \mathrm{ml} \mathrm{N1} \mathrm{N}$-dimethyl formamide, which was then added to $50 \mathrm{ml}$ Tris buffer $\left(0.2 \mathrm{~mol} \mathrm{l}^{-1}\right.$, $\left.\mathrm{pH} 7.6\right)$. Finally, $40 \mathrm{mg}$ Fast Red Violet LB salt and $12 \mathrm{mg}$ levamisole hydrochloride were added and the solution filtered. The slides were then washed for 10 min in running tap water. After rinsing in distilled water, they were counterstained in a 1:5 dilution of Harris' haematoxylin for $30 \mathrm{~s}$, rinsed again in distilled water and allowed to blue in tap water for $5 \mathrm{~min}$, before being rinsed again in distilled water and mounted in Kayser's glycerol gel (10 g gelatine in $60 \mathrm{ml}$ distilled water, plus $70 \mathrm{ml}$ glycerol and $0.25 \mathrm{~g}$ phenol).

\section{Stereology}

After a uniform random start, five consecutive $5 \mu \mathrm{m}$ sections were collected systematically every $500 \mu \mathrm{m}$. The first of the five sections was stained with haematoxylin to estimate the volume of the tissue. The next two pairs of sections were stained immunocytochemically for $\mathrm{T} 4$ helper cells and macrophages, and T8 cytotoxic cells, respectively, to estimate their number. The subsequent 95 sections were discarded before the next five sections were retained for staining and this cycle was repeated 8-10 times until the whole block had been cut.

Volume estimation was performed by applying Cavalieri's Principle (Pakkenberg and Gundersen, 1988). The cutting cycle, described above, produced a series of single sections, separated by $500 \mu \mathrm{m}$, stained with haematoxylin to calculate the reference volume of the tissue. This calculation requires the area of each section to be known, and this is achieved by point counting.

$$
\text { est } V o l_{\text {(epididymiss) }}=\sum_{i=1}^{k} \frac{p_{i} \bullet a_{p}}{m^{2}} \bullet \bar{t} \bullet n(100)
$$

Where: $p_{i}$ is the total number of points falling on all, $k$, sampled sections in the organ; $a_{p}$ is the area associated with one point of the test grid; $m$ is the linear magnification at which the section is viewed at low power; $t$ is the mean section thickness $(5 \mu \mathrm{m}$ in this case); and $n(100)$ is the number of sections between sampled sections (100 in this case).

In practice, each slide was projected at low power onto a screen using a Zeiss projecting microscope. A transparent counting grid was placed randomly onto the projected image and the number of points hitting the reference area was counted.

\section{Estimation of number of cells}

Each pair of immunocytochemically stained slides was viewed in a dual projecting microscope. This consisted of two standard light microscopes aligned side by side and positioned three feet above a large plain white projecting surface. The slides were illuminated by two high intensity light sources connected to the microscopes by fibre optic cables. The resulting images were reflected from the eyepieces down onto the white surface below by flat mirrors. This system allowed two slides in register to be projected side by side, enabling the two sections to be viewed simultaneously. Depending on the total area of the section, determined by point counting of the adjacent haematoxylin section, $1-4$ areas were assigned to each section. Under low power magnification $(\times 10)$, the slides were moved to one of the areas to be studied and a random field identifiable in both sections was selected. One slide was used as the reference slide and moved slightly from the original field of view by randomly adjusting the moveable stage. The second slide was aligned so that it projected the same field. A transparent two-dimensional sampling frame (Gundersen, 1986) was placed randomly onto the reference field. The reference field was then switched to high power $(\times 40)$ and adjusted so that the two projected fields were identical. Finally, the second sampling frame was placed on the second field in an identical position to that of the reference frame.

\section{Counting of cells}

All $\mathrm{T}$ cells not identified (stained) by the second sampling frame but identified in the reference sampling frame and not intersected by the fully drawn edge or infinite exclusion line of the sampling frame were counted. Thus, the second frame plays no part in sampling, but acts as a guide to identify particular cells present in both sections. Only unambiguously labelled cells were counted and were either scored within the epithelium (intraepithelial) or between the tubules of the epididymis, incorporating the lamina propria and interstitial connective tissue (interepithelial). The sections were then reversed, and the counting repeated.

The numerical density of cells was estimated by:

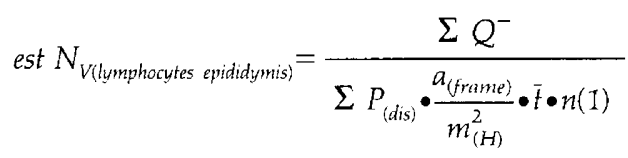

Where: $\Sigma Q^{-}$was the total of all cells counted by the dissector over all fields sampled within the organ; $\Sigma P_{(d i s)}$ was the number of dissector frames hitting the reference space. $a_{(\text {(rame) }}$ was the area of the sampling frame; $m_{(H)}$ was the linear magnification used to make the dissector counts. $\bar{t}$, the mean section thickness $(5 \mu \mathrm{m})$; and $n=1$.

The total number of cells was estimated by:

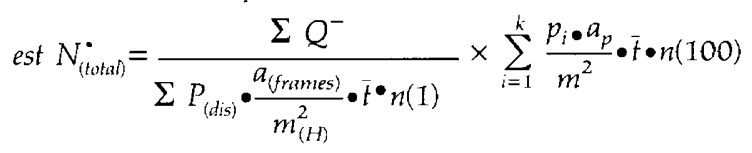

Note that $t$, the section thickness, cancels out and does not need to be known.

Finally, the microscopes were returned to low power magnification and moved randomly to the next area where the same sampling and counting procedures were repeated. This allowed 50 areas to be sampled throughout each epididymis.

\section{Statistical analysis}

The parametric Student's $t$ test was used to compare all the data from the control and experimental groups. 


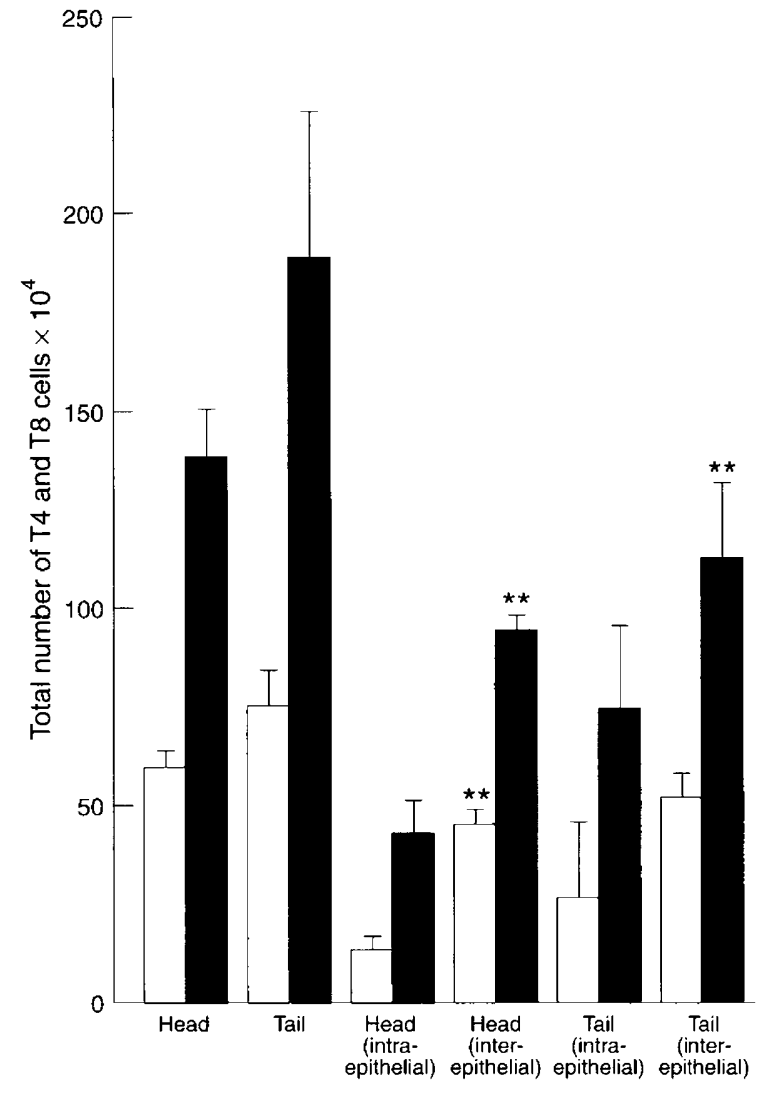

Fig. 1. Mean number (+ SEM) of ( $\square$ ) T4 helper and inducer cells and macrophages and $(\square)$ T8 suppressor and cytotoxic cells in regions of the normal rat epididymis. Significantly different from control value $(* * P<0.01)$.

\section{Cytotoxic antibody test}

The stored serum samples were analysed for cytotoxic antisperm antibodies as described by Lewis-Jones et al. (1987).

\section{Results}

\section{Immunocytochemistry}

Although the W3-25 A antibody can identify both T4 helper cells and macrophages, the vast majority of the cells identified with this antibody had the morphological characteristics of lymphocytes.

\section{Control animals}

Significantly higher numbers $(P<0.01)$ of both the T4 cells and macrophages, and the T8 cells were found in the head interepithelial location compared with the intraepithelial site (Fig. 1). In addition, there were significantly more $(P<0.01) \mathrm{T} 8$ cells in the tail interepithelial region compared with the intraepithelial site.

\section{Experimental animals}

T8 suppressor/cytotoxic cells. Within the head region, there was a significant increase $(P<0.01)$ in T8 suppressor/cytotoxic

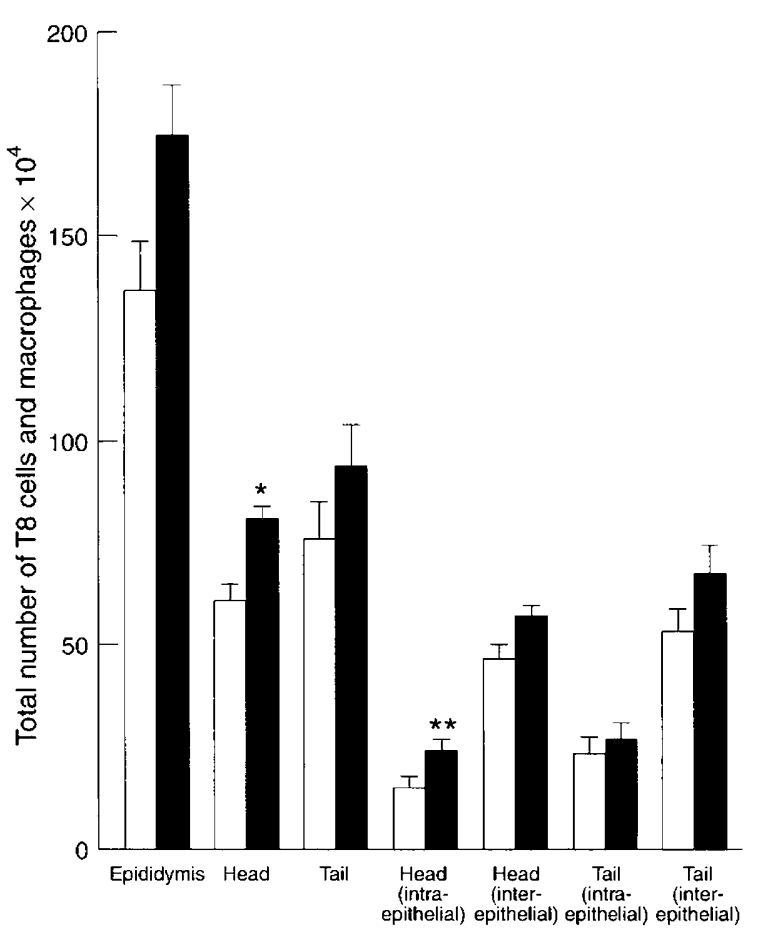

Fig. 2. Mean number ( + SEM) of T8 suppressor and cytotoxic cells in the rat epididymis and its regions $(\square)$ before and $(\boldsymbol{\square})$ after vasectomy. Significantly different from control value $(* * P<0.01$; ${ }^{*} P<0.05$ ).

cells (Fig. 2). This increase was due to a significant increase in the number of these cells in the intraepithelial location.

T4 helper cells and macrophages. There was a significant reduction in the number of T4 cells in the epididymis as a whole (Fig. 3). Within the epididymis, a significant reduction in numbers $(P<0.05)$ occurred in the interepithelial region of the head.

\section{Cytotoxic antibody test}

There was a significant decrease in the percentage of live spermatozoa in the experimental group $(P<0.01)$ after treatment with sera dilutions of $1: 3$ and 1:192, compared with the control group (Fig. 4).

\section{Discussion}

The immunocytochemical demonstration of T-cell subsets in the normal rat epididymis in this study confirms the observations of Reid and Cleland (1957) and Dym and Romrell (1975). However, in contrast to the results of Ritchie et al. (1984) and El-Demiry et al. (1985) in the human epididymis, the study reported here showed that the main T-cell phenotype present in rats is the T4 subset. In addition, significantly higher numbers of T8 and T4 subsets were found in the intercellular compartments of the head and tail of the epididymis.

Studies on autoimmunization (Johnson, 1968) have shown that cytotoxic anti-sperm antibody predominates in rats after autoimmunization. The cytotoxic antisperm antibody test described here demonstrated a significant increase in the 


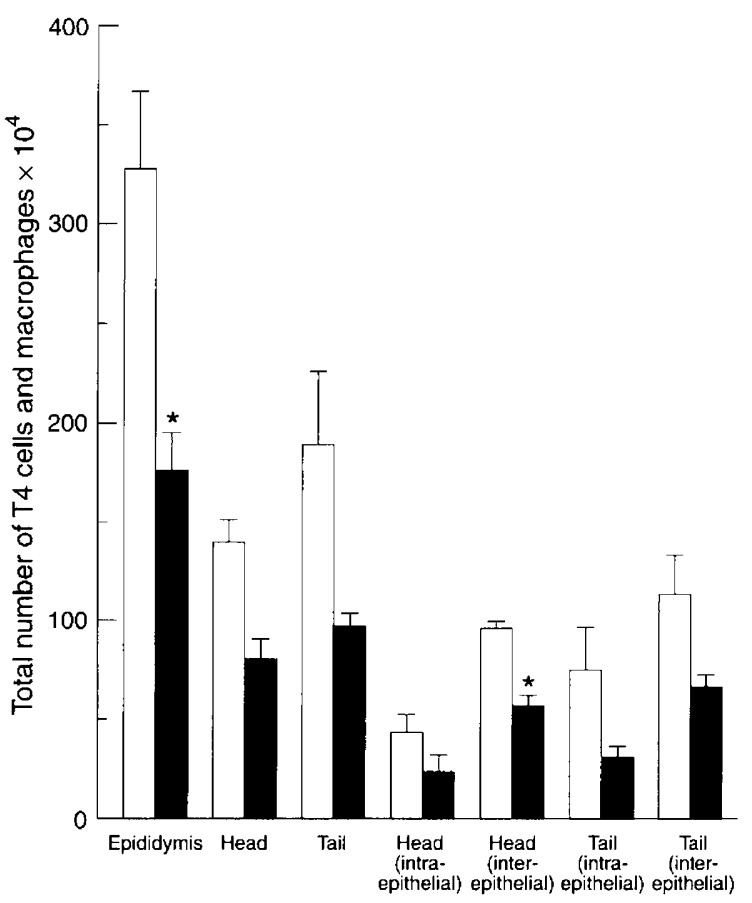

Fig. 3. Mean number ( $+\mathrm{SEM}$ ) of $\mathrm{T} 4$ helper and inducer cells and macrophages in the rat epididymis and its regions ( $\square$ ) before and (ם) after vasectomy. Significantly different from control value $\left({ }^{*} P<0.05\right)$

circulating concentration of these antibodies in the experimental group. This finding indicates that obstruction of the vas deferens causes a breakdown in immune sequestration mechanisms, allowing antigen presentation to the immune system and causing cytotoxic anti-sperm antibody production.

After vasectomy, there was a significant increase in the number of $T 8$ cytotoxic cells in the intraepithelial location of the head of the epididymis. A corresponding, significant decrease in the number of $\mathrm{T} 4$ helper cells occurred in the head interepithelial compartment. El-Demiry et al. (1985) reported an increase in T4 helper cells in biopsies of the vas deferens removed during vasectomy reversal operations. This is in direct contrast to the results in the rat epididymis presented here, where the $\mathrm{T} 4$ helper cells decrease in number and $\mathrm{T} 8$ cytotoxic celis increase in number.

Two theories regarding antigen sequestration have been advanced. The first, 'immunological sequestration', proposes that immunocompetent cells in the walls of the reproductive tract and in regional lymph nodes act to sequester gametic antigen functionally. The study reported here lends support to this theory by identifying two T-cell subsets within the epithelium and the surrounding connective tissue of the epididymis. The increase in T8 suppressor and cytotoxic cells and the decrease in T4 helper and inducer cells after vasectomy may represent part of a much wider change in the number of immunocompetent cells that occurs to counteract the increased antigen within the genital tract caused by obstruction of the efferent duct. If this is the mechanism operating in the epididymis then, in this study, the antigenic challenge appears to be far too great for effective sequestration; so autoinoculation of the immune system is effected, as demonstrated

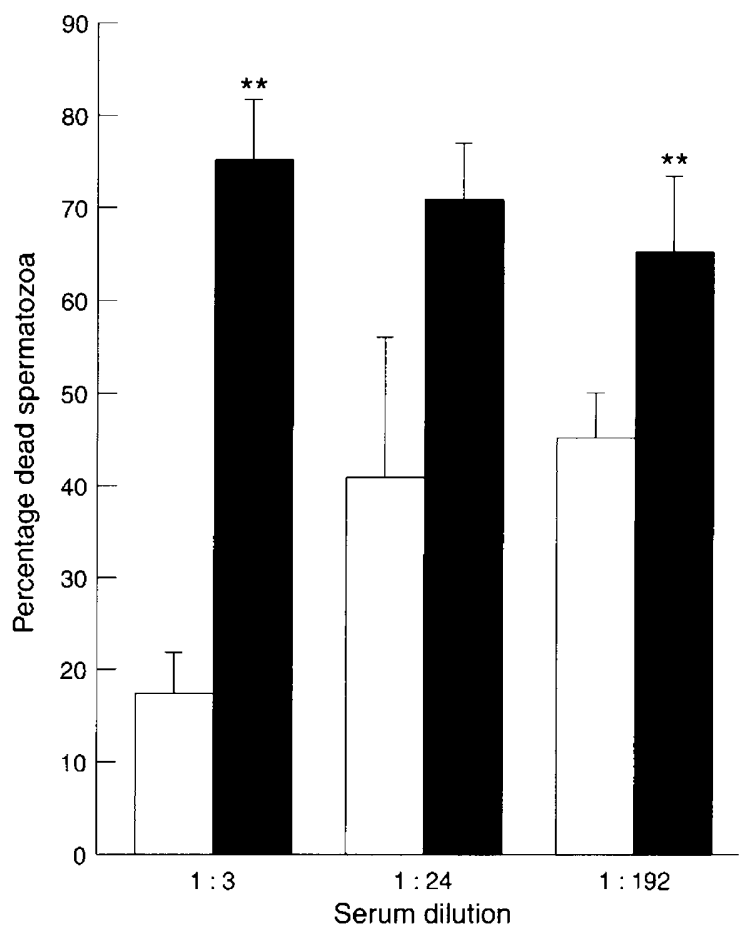

Fig. 4. Mean number ( + SEM) of dead spermatozoa, as a percentage, after incubation with sera from $(\square)$ control and ( $\square$ ) experimental rats at three different dilutions. Significantly different from control value $\left({ }^{* *} P<0.01\right)$.

by the increase in cytotoxic antisperm antibodies in the sera of experimental animals.

The second theory, 'immune tolerance' has its basis in the idea of constant low grade auto-inoculation by gradual gametic antigen build up from the start of puberty, when gametic antigen production begins. This would require the immune system to be finely tuned to a constant but small antigenic challenge, whereby unejaculated spermatozoa were degraded and the resultant sperm antigen resorbed from the epididymal lumen without the stimulation of antisperm antibody production. It is not known whether sperm antigen is absorbed in the epididymis during prepubertal spermatogenesis, but this would have to occur if immune tolerance were to develop. How such an immune tolerance mechanism would prevent antibody production is not known, but it is possible that low grade auto-inoculation by gametic antigen might stimulate $T$ suppressor activity, suppressing antigen presentation by $\mathrm{T}$ helper cells or macrophages. Thus the 'immune tolerance' theory would also require some form of immune sequestration mechanism. In the study reported here, the T8 suppressor and cytotoxic cells present in the control group may represent part of the immune tolerance mechanism. If this is the case, overloading the normal resorption and tolerance mechanisms of the epididymis, as a result of the massive antigenic challenge after vasectomy, should cause an increase in the numbers of $\mathrm{T}$ suppressor and cytotoxic cells and a decrease in T4 helper cells, inducer cells and macrophages, to suppress antigen presentation. Again, the mechanism must be overloaded, as it results in cytotoxic antisperm antibody production. It is 
possible that both immunological sequestration and immune tolerance may be present, working together.

The reason why the increase in T8 suppressor and cytotoxic cells and the decrease in the T4 helper and inducer cells occurs in the epididymal head region may be that this is the site of greatest antigenic challenge. Most studies (Crabo, 1965) support the conclusion that over $90 \%$ of testicular fluid is resorbed in the proximal portion of the epididymis (i.e., the head). After vasectomy, it is presumed that active resorption of gametic antigen will also occur in this region by the same mechanisms. Miller and Killian (1987) demonstrated that the head (caput) of the epididymis of rats possesses the structural basis for maximizing functional interactions between epididymal tissue and spermatozoa, with its small lumen and large wall volume (greatest number of columnar epithelial cells). In contrast, the large lumen and small tubular wall of the tail (cauda) of the epididymis provide the structural basis for sperm storage. They report that, after vasectomy, the number of columnar epithelial cells and lymphocytes increases in certain regions of the head of the epididymis. Thus, antigen absorption and presentation is likely to be maximal in the epididymal head and this is therefore the probable site at which the immune sequestration mechanisms combine to overcome their greatest challenge. Studies are under way to describe the distribution of T8 cells and $\mathrm{T} 4$ cells in the remainder of the reproductive tract and within the regional lymph nodes draining the area.

The authors thank E. Joughin and R. Read for expert technical assistance and $G$. Crompton for typing the manuscript. They are grateful to the Wellcome Trust for supplying financial support for this work.

\section{References}

Boyse EA, Old LJ and Chouroulinkov I (1964) Cytotoxic test for demonstration of mouse antibody Methods in Medical Research 10 39-48

Braendgaard H. Evans SM, Howard CV and Gundersen HJG (1990) The total number of neurons in the human neocortex unbiasedly estimated using optical disectors Journal of Microscopy 157 285-304

Crabo B (1965) Studies on the composition of epididymal content in bulls and boars Acta Veterinaria Scandinavica 6 Supplement 5 I-94

Dym M and Romrell LJ (1975) Intraepithelial lymphocytes in the male reproductive tract of rats and rhesus monkeys Journal of Reproduction and Fertility 42 I-7

El-Demiry MIM, Hargreave TB, Busuttil A, James K, Ritchie AWS and Chisholm GD (1985) Lymphocyte sub-populations in the male genital tract British Journal of Urology $\mathbf{5 7} 769-774$
Gundersen HJG (1986) Stereology of arbitrary particles Journal of Microscopy $143 \quad 3-45$

Halim A and Antoniou D (1973) Autoantibodies to spermatozoa in relation to male infertility and vasectomy British Journal of Urology 45 559-562

Hinchliffe SA, Sargent PH, Howard CV, Chan YF and van Velzen (1991) Human intrauterine renal growth expressed in absolute number of glomeruli assessed by the disector method and Cavalieri principle Laboratory Investigation 64 777-784

Howard V (1990) Stereological techniques in biological electron microscopy. In Biophysical Electron Microscopy pp 479-508 Eds PW Hawkes and U Valdre. Academic Press, London

Johnson M (1968) Characterisation of a natural antibody in normal guinea-pig serum reacting with homologous spermatozoa Journal of Reproduction and Fertility 16 503-506

Jones WR (1976) Immunological aspects of fertility. In Immunology of Human Reproduction pp 375-413 Eds JS Scott and WR Jones. Academic Press, London

Landsteiner K (1899) Zur Kenntnis der spezifisch auf Blutkorperchen wirkenden Sera. Centralblatt fur Bakteriologie Parasitenkunde und Intektianskrankeuheit (1.Abt., Jenna) 25 546-549

Lewis-Jones DI, Lynch RV, Kerrigan DD and Davies L (1987) The immunological consequences of sympathetic orchiopathia in the rat: a long term study Journal of Reproduction and Fertility $80641-647$

Metchnikoff E (1899) Etudes sur la resorption des cellules Annales Institute of Pasteur (Paris) 13 737-769

Miller RJ and Killian GJ (1987) Morphometric analyses of the epididymis from normal and vasectomized rats Journal of Andrology 8 279-291

Pakkenberg B and Gundersen HJG (1988) Total number of neurons and glial cells in human brain nuclei estimated by the dissector and the fractionator Journal of Microscopy 150 1-20

Phadke AM and Padukone K (1964) Presence and significance of autoantibodies against spermatozoa in the blood of men with obstructed vas deferens Journal of Reproduction and Fertility 7 163-170

Pollanen P and Cooper TG (1994) Immunology of the testicular excurrent ducts Journal of Reproductive Immunology 26 167-216

Reid BL and Cleland KW (1957) The structure and function of the epididymis I. The histology of the rat epididymis Australian Journal of Zoology 5 223-246

Ritchie AWS, Hargreave TB, James K and Chisholm GD (1984) Intraepithelial lymphocytes in the normal epididymis - a mechanism for tolerance to sperm auto-antigens? British Journal of Urology 56 79-83

Rumke PH (1954) The presence of sperm antibodies in the serum of two patients with oligospermia Vox Sanguinis 4 135-140

Rumke PH, Messer R and Bezemer PB (1974) Prognosis of fertility of men with serum agglutinins in serum Fertility and Sterility 25 393-398

Sterio DC (1984) The unbiased estimation of number and sizes of arbitrary particles using the disector Journal of Microscopy 134 127-136

Wilson $\mathrm{L}$ (1954) Sperm agglutinins in human semen and blood Proceedings of the Society for Experimental Biology and Medicine 85 652-655

Yeung $\mathrm{CH}$, Nashan D, Sorg C, Oberpenning F, Schulze H, Nieschlag E and Cooper TG (1994) Basal cells of the human epididymis - antigenic and ultrastructural similarities to tissue-fixed macrophages Biology of Reproduction 50 $917-926$ 